\title{
OPTIMAL OPERATION OF MULTIPURPOSE RESERVOIR FOR IRRIGATION PLANNING WITH CONJUNCTIVE USE OF SURFACE AND GROUNDWATER USING FUZZY RESOURCES
}

\author{
N. G. Nikam ${ }^{1}$, D. G. Regulwar ${ }^{2}$ \\ ${ }^{1}$ Research Scholar, Department of Civil Engineering, Government College of Engineering, Aurangabad, (M. S.), India \\ ${ }^{2}$ Associate Professor, Department of Civil Engineering, Government College of Engineering, Aurangabad, (M. S.),
} India

\begin{abstract}
A Fuzzy Linear programming (FLP) model has been developed with the objective of maximizing the net benefits accrued from crops in a year and subjected to constraints on availability of surface water, groundwater, culturable area, and other inputs such as reservoir storages, water requirement of crops, canal capacity and reservoir continuity. It is a conjunctive use model of surface water and ground water to obtain the optimal operating policy for a multipurpose single reservoir by considering the fuzziness involved in the resources i.e. availability of surface water, groundwater and the culturable area. The linear membership function is developed to fuzzify the resources. The developed model is applied to the case study of Jayakwadi reservoir stage-I, built across the river Godavari, Maharashtra state, India. The final model is solved for the maximized degree of satisfaction ( $\lambda$ ). The $\lambda$ obtained is equal to 0.51 and corresponding values of the objective is 3438.439 million rupees.
\end{abstract}

Keywords: Reservoir Operation, Optimal operating Policy, Conjunctive Use, Fuzzy Linear Programming, fuzzy resources

\section{INTRODUCTION}

Water scarcity is one of the issues being faced by the managers of water supply to irrigation, domestic, industrial, hydropower generation etc. It is often progressive as demand of water from all these sectors is increasing season to season or year around. An efficient management of water resource is essential, particularly in arid areas, where rainfall is erratic. Once the surface water resource gets exploited to their economic limit the next alternative is to shift to ground water. In many cases of the reservoirs, it is observed that the inflows are not sufficient to meet the demand and therefore, conjunctive use of groundwater is suggested for supplementing the water requirement of the system. Conjunctive use adds operational flexibility in surface water management by taking advantage of available ground water. It can increase yield, supply reliability and cost effectiveness for a system. Despite of significant advantage of conjunctive use, most of the irrigation and water supply schemes depend exclusively on surface water at design stage itself. Many researchers have worked on several aspects of the conjunctive use of surface and ground water such as (a) Assessment of groundwater potential. (b) Modeling of conjunctive use of surface and groundwater (c) Optimal planning using different techniques.

For groundwater recharge estimation in India, a well established rainfall recharge estimation methodology of the Groundwater Estimation Committee (GEC-1997) [5] has been used by many researchers such as by Sethi, et al. [24], Sarojini Devi et al [3], Khare et al [9] and [10]. There are many applications of optimization tools in the planning of conjunctive use of the surface and groundwater. Varieties of conjunctive use optimization models are available in the literature as applicable to reservoir systems. Yeh [26] has reviewed reservoir management and operation models. According to him optimal coordination of many facets of reservoir system requires the assistance of computer modelling tools to provide information for rational management and operational decisions. Labadie [12] has reviewed state-of-the art in optimization of multi reservoir system. Out of the most favored optimization techniques for reservoir system models is the simplex method of LP and its variants because of its ability to solve large scale problems by converging to global optimal solution. Mohan and Jothiprakash [15] developed a LP model with an objective of maximizing the net benefits accrued from the crops in a year. Then through FLP they considered the fuzziness involved in the objective function, inflow and the groundwater availability. The variation of evaporation loss due to varying water level or surface area is not considered by them.

Kashyap and Chandra [8] have developed a mathematical conjunctive use model to maximize the net benefits for arriving at an optimal conjunctive use policy incorporating spatially and temporally distributed groundwater withdrawals for predefined surface water availability for spatially distributed cropping pattern. Modelling of conjunctive use is also carried out by [1], [2], [14], and [18]. A mathematical Linear Programming model for optimal conjunctive use planning in multi crop irrigation in a canal command area to maximize the sum of annual relative yields 
of crops in a normal year have developed by Vedula et al [25]. They considered the three main components of the system as: the reservoir, irrigated area, and the underlying aquifer along with associated dynamic relationship. Regulwar and Anand Raj [19] have developed a Multi Objective Genetic Algorithm Fuzzy Optimization model which is applied to a multireservoir system. A 3-D optimal surface was evolved for deriving the optimal operation policies of the reservoir. Kamodkar and Regulwar [6] have developed a FLP model to evaluate the reservoir operation policies in which the resources were fuzzy in the first model; in the second model, the technological coefficients were fuzzified and in the third model, both the resources and the technological coefficients were considered fuzzy. However, the available groundwater potential under the command of the reservoir was not considered while working out reservoir operating policies. Regulwar and Gurav [20] and [21] have worked on the optimal cropping pattern for sustainable irrigation by maximizing different conflicting objectives simultaneously, however, without taking in to consideration the availability of groundwater in the command of the reservoir and the socio economic aspect of growing certain crops based on minimum requirement of the region, while optimizing the cropping pattern. They tackled the uncertainty in the different parameters under the fuzzy environment. Morankar et al [16] have presented an integrated approach for surface water, groundwater, industrial demand and domestic use demand on the framework of multiobjective optimization. Three membership functions namely nonlinear, hyperbolic and exponential were used for objective functions with dependable inflows for an irrigation planning. Results obtained with hyperbolic and exponential membership functions provided similar cropping patterns for most of the situations whereas nonlinear membership functions provided different copping pattern. Regulwar and Pradhan [22] have presented irrigation planning with conjunctive use but they have not considered continuity equation of the reservoir while working out the availability of the surface water from the reservoir for irrigation. Kamodkar and Regulwar [7] developed a multipurpose single-reservoir operation model by assuming triangular fuzzy-number distribution of parameters. They considered two objectives: maximization of releases for irrigation and maximization of releases for hydropower generation. Nikam and Regulwar [17] have worked out optimal operating policies for a multipurpose reservoir for irrigation planning with conjunctive use of surface and groundwater, however, without considering the fuzziness involved in various parameters of reservoir operation.

Present work deals with optimal operation of the multipurpose single reservoir for multi crop irrigation, considering continuity equation, the availability of groundwater in the command and socio economic consideration of growing certain crops based on the minimum requirement of the region by tackling the uncertainty in availability of resources under the fuzzy environment.

\section{METHODOLOGY}

The objective of the study is to maximize net benefits by suggesting an optimum irrigation release policy and a cropping pattern by use of both surface water and groundwater conjunctively by tackling the uncertainty in availability of resources under the fuzzy environment. A monthly model has been developed by considering various variables such as irrigation demand, land use restrictions, socio economic constraint, drinking water demand, industrial water demand, live storage restrictions, canal capacity restrictions and availability of groundwater. Present work deals with FLP for multi crop irrigation, considering continuity equation of the reservoir and fuzzy resources such as surface water availability, groundwater availability and the available culturable area. Also optimal reservoir operation policies are obtained.

To develop a FLP model, initially a Linear Programming (LP) model has been developed with the objective function of maximizing the net benefits accrued from crops in Kharif, Rabi, Bi-seasonal, Hot Weather and Perennial seasons in a year. The language for Interactive General Optimization (LINGO) has been used to solve the linear optimization problem.

The classical linear programming problem in its general form is as follows:

$$
\begin{aligned}
& \operatorname{Max} Z=\sum_{j=1}^{n} c_{j} x_{j} \\
& \text { Subject to: } \sum_{j=1}^{n} a_{i j} x_{j} \leq b_{i} \quad\left(i \in N_{m}\right) \\
& x_{j} \geq \mathbf{O} \quad\left(j \in N_{n}\right)
\end{aligned}
$$

Where,

$Z$ is the objective function; $x_{j}$ is the set of decision variables; and $c_{j}, a_{i j}$, and $b_{i}$, are the coefficients of the model namely objective function coefficient, technological coefficient and resources respectively. The numerical values of these model parameters are considered as deterministic in the classical Liner Programming model.

\subsection{Reservoir Operation Model in the Present}

\section{Study}

In the present study, a linear programming reservoir operation model is developed for Irrigation Planning with Conjunctive use of surface and groundwater. Model considers the objective of maximizing the net benefits from the available water resource from the command of a reservoir. It is expressed as:

$$
\begin{aligned}
\operatorname{Max} Z= & \sum_{z=1}^{n z} \sum_{c=1}^{n c} N B_{z c} A_{z c}-\sum_{z=1}^{n z} \sum_{t=1}^{12} C S W_{z t} \eta_{s} S W A_{z t} \\
& -\sum_{z=1}^{n z} \sum_{t=1}^{12} C G W_{z t} \eta_{g} G W A_{z t} \quad(\text { Eqn.2) }
\end{aligned}
$$


Where,

$Z=$ Total net benefit i.e. value of objective function in Rs

$N B_{z c}=$ It is net benefit estimated from irrigation of $c^{\text {th }}$ crop from $\mathrm{z}^{t h}$ canal zone.

$A_{z c}=$ Area under the $c^{\text {th }}$ crop in $\mathrm{m}^{2}$ grown in $z^{\text {th }}$ canal zone.

$C S W_{z t}=$ Total cost of providing surface water during $t^{\text {th }}$ month in $z^{\text {th }}$ zone.

$\eta_{s}$ is efficiency of surface water system.

$S W A_{z t}=$ Surface water available at the head of the $z^{\text {th }}$ canal at $t^{\text {th }}$ time period.

$C G W_{z t}=$ Total cost of providing groundwater during $t^{\text {th }}$ month in $z^{\text {th }}$ zone. It also includes the capital cost, pumping cost, operation and maintenance cost.

$\eta_{g}$ is the efficiency of groundwater.

$G W A_{z t}=$ Available groundwater in $z^{\text {th }}$ zone during time period $t^{\text {th }}$ without allowing mining.

\subsection{Constraints}

The objective function of maximization of net benefit is subjected to the following constraints such as:

\subsubsection{Land Area Constraint}

The total area allocated for different crops in a particular season should be less than or equal to the total culturable command area (TCCA) available during that season.

Season wise area constraints are given below:

\subsubsection{Kharif Crops Area Constraint}

$\sum_{z=1}^{n z} \sum_{c=1}^{n k c} A_{z c} \leq T C C A_{z k}$

(Eqn.3)

Where,

$T C C A_{z c}=$ Total culturable command area during Kharif season in $z^{\text {th }}$ canal zone.

$c=1$ to $n k c$ Crops in Kharif season,

\subsubsection{Rabi Crops Area Constraint}

$\sum_{z=1}^{n z} \sum_{c=1}^{n r c} A_{z c} \leq T C C A_{z r}$

(Eqn.4)

$T C C A_{z r}=$ Total culturable command area during rabi season in $z^{\text {th }}$ canal zone.

$c=1$ to $n r c$ Crops in rabi season

\subsubsection{Bi-seasonal Crops Area Constraint}

$\sum_{z=1}^{n z} \sum_{c=1}^{n b c} A_{z c} \leq T C C A_{z b}$

$T C C A_{z b}=$ Total culturable command area during bi season in $z^{\text {th }}$ canal zone.

$c=1$ to $n b c$ crops in bi-season

\subsubsection{Hot Weather Crops Area Constraint}

$\sum_{z=1}^{n z} \sum_{c=1}^{n h c} A_{z c} \leq T C C A_{z h}$

$T C C A_{z h}=$ Total culturable command area during hot weather season in $z^{\text {th }}$ canal zone.

$c=1$ to $n h c$ crops in hot weather

\subsubsection{Perennial Crops Area Constraint}

$\sum_{z=1}^{n z} \sum_{c=1}^{n p c} A_{z c} \leq T C C A_{z p}$

$T C C A_{z p}=$ Total culturable command area during perennial season in $z^{\text {th }}$ canal zone.

$c=1$ to $n p c$ crops in perennial season

\subsubsection{Crop Area Constraint}

It is also called as socio economic constraint which restricts irrigated area under the crops in a particular season to certain minimum value to meet the requirement of food of local population.

$$
A_{c}=P_{c} * T C C A
$$

$P_{c}=$ It is the percentage of $C^{\text {th }}$ crop in $Z^{\text {th }}$ canal zone with respect to $T C C A$.

\subsubsection{Constraint with respect to Total Water Requirement of Crops}

Net irrigation water requirement by all crops during time period $t$ in each zone is to be satisfied from monthly available surface water and groundwater at the field.

$$
\begin{aligned}
\sum_{z=1}^{n z} \sum_{t=1}^{12} & \sum_{c=1}^{n c} N I W R_{z t c} A_{z t c} \leq \eta_{s}\left(\sum_{z=1}^{n z} \sum_{t=1}^{12} S W A_{z t}\right) \\
+\eta_{g}\left(\sum_{z=1}^{n z} \sum_{t=1}^{12} G W A_{z t}\right) & (\text { Eqn.9) }
\end{aligned}
$$

$A_{z t c}=$ Area of $c^{\text {th }}$ crop under canal zone $z$ during time period $t$.

$\eta_{s}$ and $\eta_{g}$ are efficiencies of surface water and groundwater systems respectively.

\subsubsection{Canal Capacity Constraints}

Releases from the reservoir in the canal during the time period $t$ should be less than or equal to the canal capacity in each zone during the time period $t$.

$$
S W A_{z t} \leq C C_{z t}
$$

$C C_{z t}=$ Capacity of $z^{\text {th }}$ canal during time period $t$, (i.e. per month in $\mathrm{m}^{3}$ ). 


\subsubsection{Reservoir Storage Constraint}

The live storage in the reservoir in any time period $t$ should be less than or equal to the maximum capacity and should be more than or equal to and the dead storage.

$$
S_{\min } \leq S_{t} \leq S_{\max }
$$

$S_{t}=$ reservoir storage at the beginning of the month $t(t=1$, $2, \ldots, 12)$

\subsubsection{Continuity Constraint}

The continuity constraint involves releases, overflows, storages, inflows and losses through the reservoir during the period ' $\mathrm{t}$ ' i.e. for period $t$ expressed in unit of volume. The evaporation losses are expressed as function of storage. The storage continuity equation given by Loucks et al [13] is adopted.

$$
\begin{aligned}
\left(1+a_{t}\right) S_{t+1}= & \left(1-a_{t}\right) S_{t}+I_{t}-\sum_{z=1}^{n z} \sum_{t=1}^{12} S W A_{z t} \\
& -R_{t}-A_{0} E_{t}-O_{t}
\end{aligned}
$$

Where,

$a_{t}=0.5 A_{a} * E t$

$E_{t}=$ Average evaporation rate for each period.

$A_{a}=$ Area corresponding to month wise average storage

$A_{0}=$ Surface area corresponding to dead storage

$S_{t}=$ is reservoir storage at the beginning of the month $t$,

$S_{t+l}=$ reservoir storage at the end of the month $t$ and also at the beginning storage at the month $t+1$, i.e. storage in the next time stage

$R_{t}=$ Releases other than irrigation

$I_{t}=$ inflow in the reservoir during month $t$

$O_{t}=$ the overflow from the reservoir during month $t$, it should be greater than zero

\subsection{Fuzzy Linear Programming}

A FLP model has been formulated by considering the fuzziness involved in the resources such as availability of surface water, groundwater and the culturable area under each Canal Zone for each crop.

\subsubsection{Fuzzification of Resources (Bi fuzzification)}

In order to improve the applicability of reservoir operation model described in preceding section, the uncertainties involved in the resources have been considered through FLP. Lamda $(\lambda)$ the Degree of Satisfaction within the fuzzy set is represented by the membership function. A general form of FLP in which only the right hand side numbers i.e. resources are fuzzy numbers is as follow:

$$
\operatorname{Max} \sum_{j=1}^{n} C_{j} X_{j}
$$

Subject to:

$$
\begin{array}{lc}
\sum_{j=1}^{n} A_{i j} X_{j} \leq \tilde{b}_{i} & (i \in \square \mathrm{m}) \\
\tilde{b}_{i}=\left[b_{i}^{L}, b_{i}^{U}\right] & \text { where } b_{i}^{U}=\left(b_{i}^{L}+p_{i}\right) \\
X j \geq 0 & (j \in \square n)
\end{array}
$$

\begin{tabular}{|c|c|c|}
\hline$B_{i}(x)$ & $\begin{array}{l}1 \\
(b i+p i)\end{array}$ & $\begin{array}{l}\text { when } x \leq b i \\
\text { when } b i \prec x \prec b i+p i\end{array}$ \\
\hline & 0 & when $b i+p i \leq x$ \\
\hline
\end{tabular}

Fuzzy numbers $\mathrm{Bi}\left(i \in N_{m}\right)$ in this case typically have the form:

Where, $x \in R$

(Eqn.14)

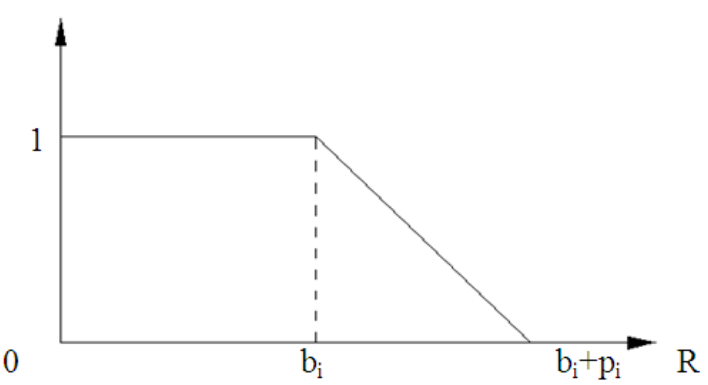

For each vector $\mathrm{x}=\left(\mathrm{x}_{1}, \mathrm{x}_{2} \ldots \mathrm{x}_{\mathrm{n}}\right)$, we first calculate the degree, $D_{i}(x)$, to which $x$ satisfies the $i^{\text {th }}$ constraint $\left(i \in N_{m}\right)$ by formula

$$
\operatorname{Di}(x)=B i\left(\sum_{j=1}^{n} a_{i j} x_{j}\right)
$$

These degrees are fuzzy sets on $\mathrm{R}^{\mathrm{n}}$, and their intersection $\bigcap_{i=1}^{m} D_{i}$, is a fuzzy feasible set.

Next, we determine the fuzzy set of optimal values. This is done by calculating the lower and upper bounds of the optimal values first. The lower bound of the optimal values, $\mathrm{z}_{\mathrm{l}}$, is obtained by solving the standard linear programming problem.

$\operatorname{Max} z=c x$

$$
\begin{aligned}
\text { s.t. } \quad \sum a_{i j} x_{j} \leq b_{i} \quad\left(i \in N_{m}\right) \\
x_{j} \geq 0 \quad\left(j \in N_{n}\right)
\end{aligned}
$$

The upper bound of the optimal values ' $\mathrm{z}_{\mathrm{u}}$ ' is obtained by a similar linear programming problem in which each $b_{i}$ is replaced with $b_{i}+p_{i}$ 
$\operatorname{Max} z=c x$

$$
\begin{gathered}
\text { s.t. } \quad \sum a_{i j} x_{j} \leq b_{i}+p_{i} \quad\left(i \in N_{m}\right) \\
x_{j} \geq 0 \quad\left(j \in N_{n}\right)
\end{gathered}
$$

Then, the fuzzy set of optimal values, G, which is fuzzy subset of $\mathrm{R}^{\mathrm{n}}$, is defined by

$$
\begin{aligned}
& 1 \quad \text { when } z_{u} \leq c x \text {, } \\
& G(x) \quad \frac{c x-z_{l}}{z_{u}-z_{l}} \quad \text { when } z_{l} \leq c x \leq z_{u} \text {, } \\
& 0 \quad \text { when } c x \leq z_{l}, \quad \text { (Eqn.17) }
\end{aligned}
$$

Now, the problem of resource fuzzification becomes the following classical optimization problem.

$\operatorname{Max} \lambda$

$$
\begin{array}{ll}
\text { s.t. } & \lambda\left(z_{u}-z_{l}\right)-c x \leq-z_{l} \\
& \lambda p_{i}+\sum_{i=1}^{n} a_{i j} x_{j} \leq b_{i}+p_{i} \\
& \lambda, x_{j} \geq 0\left(j \in N_{n}\right)
\end{array}
$$

The above problem is actually, a problem of finding $\boldsymbol{x} \in \boldsymbol{R}^{n}$ such that $\left[\left(\bigcap_{i=1}^{m} D_{i}\right) \cap G\right](x)$ reaches the maximum value; that is, a problem of finding a point which satisfies the constraints and goal with the maximum degree. The symmetric method in which the constraints and the goal are treated symmetrically is employed here. [11]

\section{DESCRIPTION OF THE STUDY AREA}

The developed model is applied to the case study of Jayakwadi reservoir stage-I on the river Godavari in the State of Maharashatra, (India). The Fig.1 shows the location of Jayakwadi reservoir stage-I. It is a multipurpose project with gross and live storage capacities $2909 \mathrm{Mm}^{3}$ and 2170 $\mathrm{Mm}^{3}$ respectively. The system of two canals i.e. Left Bank Canal $208 \mathrm{~km}$ in length and the Right Bank Canal $132 \mathrm{~km}$ in length serves an irrigable command area of 141640 ha and 41700 ha respectively. The reservoir has a pump storage power generation unit with $12 \mathrm{MW}$ reversible pump turbine unit at the foot of the dam. The entire command area of the project lies within the Latitude $18^{\circ} 46^{\prime} \mathrm{N}$ to $19^{0} 30^{\prime} \mathrm{N}$ and Longitude $75^{\circ} 20$ ' $\mathrm{E}$ to $77^{0} 45^{\prime} \mathrm{E}$.

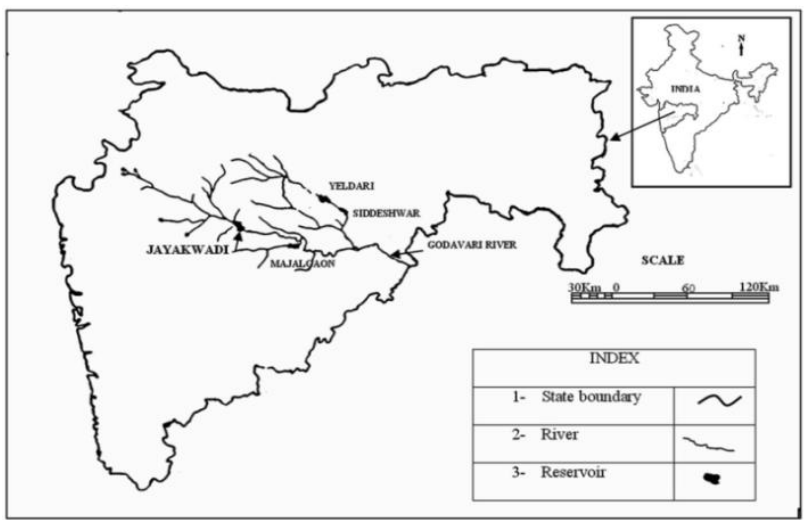

Fig.1. The location map of Jayakwadi reservoir stage-I

The total intensity of irrigation of Jayakwadi reservoir stage I is $102 \%$ distributed in $22 \%$ for kharif crops (Jowar $12 \%$ and Paddy 10\%), 45\% for rabi crops (Wheat 25\%, Jowar $15 \%$ and Gram 5\%), $28 \%$ for two seasonal crops (Cotton $25 \%$ and chilly $3 \%$ ), $3 \%$ for hot heather ground nut and $4.5 \%$ for perennial crops (Sugarcane $3 \%$ and Banana 1.5\%).

\section{MAJOR CONSIDERATIONS IN FORMULATION OF THE PROBLEM AND EVALUATION OF ITS PARAMETERS}

1. The model considers the $75 \%$ dependable inflows in to the reservoir and same is considered as the upper value of the surface water resource.

2. Crops are considered to be grown throughout the year in five different seasons i.e. Kharif, Rabi, Bi-seasonal, Hot weather and Perennial. The area under different crops as per the project cropping pattern is considered as upper limit for crop area resource.

3. It is observed that the utilization of the groundwater is not uniform throughout the year. Farmers use more groundwater during the post monsoon period and before hot weather. It is, therefore, suitably assumed in absence of the data that about $60 \%$ of the total available groundwater would be utilized equally during October to March and rest during the remaining part of the year. This is considered as the upper value of the groundwater resource.

4. Releases for power generation in the pump storage power station are restricted between the monthly turbine capacity of $33.96 \mathrm{Mm}^{3}$ and minimum release for firm power as $22.67 \mathrm{Mm}^{3}$.

5. Month wise heads over the turbine are worked out from the storage- elevation curve of the reservoir.

6. Other uses of water considered in continuity equation are [23]:

(a) Releases for water supply $31.63 \mathrm{Mm}^{3}$ per month

(b) Feeder canal releases for downstream storages during October to February as $50 \mathrm{Mm}^{3}, 80 \mathrm{Mm}^{3}$, $70 \mathrm{Mm}^{3}, 90 \mathrm{Mm}^{3}$, and $60 \mathrm{Mm}^{3}$ respectively.

7. $10 \%$ of the releases for the power generation in pump storage power station are considered as losses.

8. Evaporation losses which are worked out by considering the month wise variation of the surface area given by Loucks et al [13]. 
9. Available groundwater from recharge in the command without allowing mining is estimated using lumped empirical approach and guidelines of GEC-97.Based on the joint work of the Central Ground Water Board, Government of India and Ground Water Survey and Development Agency (GSDA) of Government of Maharashtra [4] on the estimation of groundwater resource of Aurangabad district about $16 \%$ of the total precipitation joins to the groundwater.

10. The cost of providing surface water is based on the local government norms and the cost of the groundwater is calculated by considering the capital cost, pumping cost, operation and maintenance cost.

11. Irrigation water requirement is considered at the canal outlets and that of groundwater at source by considering conveyance efficiencies as $60 \%$ and $80 \%$ respectively.

12. Net Water Requirement of crop during the time period $t$ is estimated by modified Penman Method.

13. In formulation of FLP the lower values of the resources are considered $15 \%$ less than their upper values.

\section{RESULTS AND DISCUSSIONS}

The reservoir operation model as discussed in the sections 2.1 and 2.2 is applied to the case study of Jayakwadi reservoir stage-I by taking into account all considerations and the evaluated parameters as stated in sections 4 . Then a FLP model has been formulated as discussed in section 2.3.The other parameters of the model i.e. the technological coefficients $\left(a_{i j}\right)$ and the cost coefficients $\left(c_{i}\right)$ are crisp in nature. The upper bound of the optimal value of net benefits is estimated by considering the $100 \%$ availability of resources and the lower bound is estimated by restricting the resources $15 \%$ less than the available. The linear membership function described by equation 14 is used to define the fuzzy set of optimal values. The values of upper and lower bounds of objective function i.e. net benefit from the crops are 3590.0 Million Rupees and 3279.72 Million Rupees respectively. By incorporating the information obtained from the equations 15, 16 and 17, the optimized value which satisfies the constraints and goal with a maximum degree of satisfaction lamda $(\lambda)$ is achieved by solving the problem of fuzzification as stated in equation 18 . It is similar to the classical optimization problem for maximization of $\lambda$ and it is solved for $\lambda$ which is 0.511 . Runs were made to obtain optimal results namely net benefits, cropping pattern, surface water releases, groundwater pumpage, storages at the end of every month and corresponding head over the turbine. These results are compared with that obtained from a classical linear programming model.

\subsection{Optimal Cropping Patterns}

The optimal cropping patterns obtained in all three cases as discussed in the earlier section are presented in table 1 . It is observed that while solving the linear programming problem for upper bound and lower bound of the resources the area allocated to gram in Rabi season is increased from zero to $44.5 \%$ respectively. Also the area under the Kharif paddy is increased from $11.85 \%$ to $39.44 \%$. This is due to restricting of land resource by $15 \%$ under the crops with relatively higher benefit coefficients while solving the linear programming problem with lower bound. Such crops are Kharif Jawar, Bi- Seasonal Cotton, Bi-seasonal Chilly and Perennial Sugarcane which have got almost $100 \%$ allotment of area while considering upper bound of resources. This has resulted in very marginal reduction in intensity of irrigation such as from $58.48 \%$ in case of upper bound to $57.37 \%$ in case of lower bound. Though the net benefits have been reduced by $8.64 \%$, it has helped to bring more area under the crops Kharif Paddy, Rabi Gram and Hot Weather Groundnut which will help to cater need of local population.

A compromise solution obtained through fuzzification of resources is also presented in Table 1 . It is observed that there is hardly any change in the intensity of irrigation as compared to the cases of upper and lower bound of the resources. Even the net benefit is just $4.22 \%$ less as compared to the case of upper bound of the resources. It has resulted into allotment of area to almost all crops. Thus, it has helped to take into account the socio economic constraint of growing all crops for the need of the local population. It is thus, as a result of optimization of resources in a fuzzy environment with a satisfaction level up to 0.511 taking care of the vagueness and uncertainties in the availability of resources.

Being a multipurpose reservoir, after giving first priorities to the water supply for drinking and industrial use the optimal releases for irrigation are obtained from the model as shown in Table 2 for all these three cases. The entire available amount of surface water is almost utilized for deriving the optimal cropping pattern in all the three cases which is in the tune of $1055 \mathrm{Mm}^{3}$. At the same time the available groundwater is also utilized to its fullest extent of 132.30 $\mathrm{Mm}^{3}$ in all the three cases.

The live storage value at the end of June in all the three cases is observed to be zero, where as it is maximum at the end of October but still less than the maximum gross storage capacity of $2909 \mathrm{Mm}^{3}$ of the reservoir. Thus, there is no spill over the dam in any of the months.

\subsection{Optimal Monthly Canal Releases and Storages}

The canal wise optimal monthly releases and the gross storage at the end of every month for all three cases obtained from the model are shown in Table 2.The head over the turbine at the end of every month and power generated per month are also obtained from the model for all these three cases.

The monthly release of surface water from the reservoir for power generation is at its minimum requirement of 22.67 $\mathrm{Mm}^{3}$ for firm power generation in all three cases. There is negligible variation in the values of head over the turbine and the corresponding power generated by the turbine in all the three cases. The average power generated in the pump storage power generation unit is $1.66 \mathrm{MW}$ per month under an average head of $27 \mathrm{~m}$ available over the turbines in all the three cases. 
Maximum releases are observed in the month of October and November. At the same time no surface water releases are there in the months of July and August due to low irrigation demand because of precipitation.

\section{CONCLUSION}

The vagueness and uncertainties in the availability of resources are tackled to evolve an optimal operation model of multipurpose reservoir for irrigation planning with conjunctive use of surface and groundwater using FLP. The evolved model is applied to a case study of Jayakwadi reservoir stage-I, Maharashatra State, India. Following conclusions are drawn from the study.

Table 1: Optimal cropping patterns obtained from the model by considering the upper and lower values of the resources and after fuzzification of resources.

\begin{tabular}{|c|c|c|c|c|c|c|c|}
\hline \multirow[b]{2}{*}{$\begin{array}{l}\text { Crop } \\
\text { Notation }\end{array}$} & \multirow[b]{2}{*}{ Crop Name } & \multicolumn{2}{|c|}{$\begin{array}{l}\text { Optimal cropping pattern } \\
\text { by considering upper value } \\
\text { of the resources }\end{array}$} & \multicolumn{2}{|c|}{$\begin{array}{l}\text { Optimal cropping pattern } \\
\text { by considering the lower } \\
\text { value of the resources }\end{array}$} & \multicolumn{2}{|c|}{$\begin{array}{l}\text { Optimal cropping pattern } \\
\text { obtained after fuzzification } \\
\text { of resources }\end{array}$} \\
\hline & & $\begin{array}{l}\text { Area under } \\
\text { the crop in } \\
\text { ha }\end{array}$ & $\begin{array}{l}\text { Its \% over } \\
\text { total } \\
\text { available } \\
\text { irrigable } \\
\text { command } \\
\text { area }\end{array}$ & $\begin{array}{l}\text { Area under } \\
\text { the crop in } \\
\text { ha }\end{array}$ & $\begin{array}{l}\text { Its \% over } \\
\text { total } \\
\text { available } \\
\text { irrigable } \\
\text { command } \\
\text { area }\end{array}$ & $\begin{array}{l}\text { Area under } \\
\text { the crop in } \\
\text { ha }\end{array}$ & $\begin{array}{l}\text { Its \% over } \\
\text { total } \\
\text { available } \\
\text { irrigable } \\
\text { command } \\
\text { area }\end{array}$ \\
\hline A1 & Kharif Jawar & 22000.8 & 100 & 18700.6 & 85 & 20312.7 & 92.33 \\
\hline $\mathrm{A} 2$ & Kharif Paddy & 2174.2 & 11.85 & 7230.8 & 39.44 & 1973.9 & 10.76 \\
\hline A3 & Rabi Wheat & 13750.5 & 30 & 11687.8 & 25.5 & 12695.4 & 27.69 \\
\hline A4 & Rabi Jawar & 8250.3 & 30 & 7012.7 & 25.5 & 7617.2 & 27.69 \\
\hline A5 & Rabi Gram & 0 & 0 & 7791.9 & 44.5 & 5731.1 & 32.74 \\
\hline A6 & Bi-Seasonal Cotton & 45835 & 100 & 38959.7 & 85 & 42318.3 & 92.33 \\
\hline A7 & Bi-seasonal Chilly & 5500.2 & 100 & 4675.1 & 85 & 5078.1 & 92.32 \\
\hline A8 & $\begin{array}{ll}\text { Hot } & \text { Weather } \\
\text { Groundnut } & \\
\end{array}$ & 1650 & 30 & 2124.9 & 38.63 & 1523.4 & 27.69 \\
\hline A9 & Perennial Sugarcane & 5318.7 & 96.7 & 4675.1 & 85 & 5078.1 & 92.32 \\
\hline A10 & Perennial Banana & 2750.1 & 81.5 & 2337.5 & 69.24 & 2539 & 75.21 \\
\hline \multicolumn{2}{|c|}{ Net Cropped Area } & 107229.8 & 58.48 & 105196.1 & 57.37 & 104867.2 & 57.19 \\
\hline \multicolumn{2}{|c|}{ Intensity of irrigation (\%) } & \multicolumn{2}{|l|}{58.48} & \multicolumn{2}{|l|}{57.37} & \multicolumn{2}{|l|}{57.19} \\
\hline \multicolumn{2}{|c|}{ Net benefits in Million Rs } & \multicolumn{2}{|l|}{3590} & \multicolumn{2}{|l|}{3279.72} & \multicolumn{2}{|l|}{3438.439} \\
\hline
\end{tabular}

Table 2: Monthly releases and storages in the reservoir at the end of every month obtained by considering upper and lower bound of resources and fuzzification of resources.

\begin{tabular}{|c|c|c|c|c|c|c|c|}
\hline \multirow[t]{2}{*}{$\begin{array}{l}\text { Sr. } \\
\text { No. }\end{array}$} & \multirow[t]{2}{*}{ Month } & \multicolumn{2}{|c|}{$\begin{array}{l}\text { Optimal releases for } \\
\text { irrigation and gross } \\
\text { storages by considering } \\
\text { upper value of the } \\
\text { resources }\end{array}$} & \multicolumn{2}{|c|}{$\begin{array}{l}\text { Optimal releases for } \\
\text { irrigation and gross } \\
\text { storages by considering } \\
\text { lower value of the } \\
\text { resources }\end{array}$} & \multicolumn{2}{|c|}{$\begin{array}{l}\text { Optimal releases for } \\
\text { irrigation and gross } \\
\text { storages after fuzzification } \\
\text { of resources }\end{array}$} \\
\hline & & $\begin{array}{l}\text { Releases in } \\
\mathrm{Mm}^{3}\end{array}$ & $\begin{array}{l}\text { Gross } \\
\text { Storage } \\
\text { in } \mathrm{Mm}^{3}\end{array}$ & $\begin{array}{l}\text { Releases in } \\
\mathrm{Mm}^{3}\end{array}$ & $\begin{array}{l}\text { Gross } \\
\text { Storage } \\
\text { in } \mathrm{Mm}^{3}\end{array}$ & $\begin{array}{l}\text { Releases in } \\
\mathrm{Mm}^{3}\end{array}$ & $\begin{array}{l}\text { Gross } \\
\text { Storage } \\
\text { in } \mathrm{Mm}^{3}\end{array}$ \\
\hline 01 & June & 18.29 & 738.000 & 16.18 & 738.000 & 17.59 & 738.00 \\
\hline 02 & July & 00.00 & 774.927 & 10.87 & 776.99 & 00.00 & 775.61 \\
\hline 03 & August & 00.00 & 1097.177 & 8.51 & 1088.44 & 00.00 & 1097.85 \\
\hline 04 & September & 62.38 & 1617.637 & 69.52 & 1600.67 & 57.65 & 1618.29 \\
\hline 05 & October & 266.52 & 2054.431 & 285.94 & 2030.76 & 275.20 & 2059.75 \\
\hline 06 & November & 200.25 & 1933.262 & 208.39 & 1890.79 & 213.20 & 1929.89 \\
\hline 07 & December & 100.47 & 1767.076 & 109.30 & 1717.20 & 110.55 & 1750.90 \\
\hline 08 & January & 121.65 & 1652.498 & 104.08 & 1594.45 & 113.04 & 1626.49 \\
\hline 09 & February & 57.80 & 1401.272 & 50.01 & 1361.57 & 54.32 & 1384.21 \\
\hline 10 & March & 59.83 & 1231.073 & 51.97 & 1199.73 & 56.45 & 1217.74 \\
\hline 11 & April & 89.66 & 1076.507 & 77.81 & 1053.95 & 84.52 & 1066.94 \\
\hline 12 & May & 76.43 & 882.613 & 66.65 & 872.63 & 72.39 & 878.50 \\
\hline Total & & 1053.3 & -- & 1059.3 & -- & 1054.91 & -- \\
\hline
\end{tabular}


1. The available fuzzy resources such as surface water, groundwater and the culturable land area are optimized under the fuzzy environment with a satisfaction level up to 0.511 taking care of the vagueness and uncertainties in them.

2. The intensity of irrigation for upper bound, lower bound of the resources and for fuzzy optimization problem are observed as $58.48 \%, 57.37 \%$ and $57.19 \%$ respectively with corresponding maximized net benefit values of objective function in million Rs as 3590.0, 3279.72 and 3438.439 respectively.

3. The fuzzification of resources through a compromise solution has resulted in allocation of culturable area to all the crops which have helped to cater the need of the local population.

4. Being a multipurpose reservoir, after giving first priority to water supply, the optimal cropping patterns and the optimal operating policies are obtained as discussed in the section 5 .

5. Fuzzy Logic effectively handles the uncertainties or the vagueness in the availability of the resources while deriving the optimal water use policies to estimate the maximum returns from the system.

\section{ACKNOWLEDGEMENTS}

The authors are thankful to the Command Area Development Authority, Aurangabad, Maharashatra State, India for providing necessary data for analysis.

\section{REFERENCES:}

[1] Azaiez, M. N. (2002). “Operation Research Applications: A model for conjunctive use of ground and surface water with opportunity costs", European Jr. of Operational Research, 123, pp. 611-624.

[2] Azaiez, M. N., and Hariga, M. (2001). "Theory and methodology: A single-period model for conjunctive use of ground and surface water under severe overdrafts and water deficit", European Journal of Operational Research, Vol.133, pp. 653-666.

[3] Devi, B. Sarojini, Ranghaswami, M. V., and Mayilswami, C. (2012). "Groundwater resources assessment and conjunctive use modelling for multipurpose irrigation in PAN basin, India", Water Week 2012- Water, Energy and Food Security: call for solutions, New Delhi.

[4] Government of India, Ministry of Water Resources, Central Ground Water Board, 1646/DBR/2010.

[5] Groundwater Resource Estimation Methodology 1997, "Report of Groundwater Resource Estimation Committee, Ministry of Water Resources, Government of India, New Delhi.

[6] Kamodkar, R. U., and Regulwar, D. G. (2010). "Derivation of multipurpose single reservoir release policies with fuzzy constraints", Journal of Water Resource and Protection, Vol. 2, (12), pp. 10281039.

[7] Kamodkar, R. U., and Regulwar, D. G. (2014). "Optimal multiobjective reservoir operation with fuzzy decision variables and resources: A compromise approach", Journal of Hydroenvironment Research, Vol. 8, (4), pp. 428-440.

[8] Kashyap, D. and Chandra, S. (1982). "A distributed conjunctive use model for optimal cropping pattern", Proceedings of the Exeter Symposium, IASH, (135), pp. 377-384.

[9] Khare D., Jat, M. K., and Ediwahyunan (2006). "Assessment of conjunctive use planning options: A case study of Sapan irrigation command area of Indonesia", Journal of Hydrology, Vol. 328, pp. 764777.

[10] Khare, D., Jat, M. K., and Sunder, J. D. (2007). "Assessment of water resources allocation potions: Conjunctive use planning in a link canal command (Krishna-Nagarjunsagar and Pennar-Somasila canal)", Resource, Conservation \& Recycling, Vol. 51, pp. 487-506

[11] Klir, George J. and Yuan, B. (2002). "Fuzzy sets and fuzzy logic (Theory and Applications)", PrenticeHall of India, New Delhi.

[12] Labadie, J. W. (2004). "Optimal operation of multireservoir systems: State-of-the-art review", Journal of Water Resources Planning and Management, American Society of Civil Engineers (ASCE), Vol.130, (2), pp. 93-111.

[13] Loucks, D. P., Stendinger, J. R., and Haith, D. A. (1981). "Water resources system planning and analysis", Prentice Hall, Englewood Cliff, New Jersey, pp. 231-243.

[14] Manuel Pulido-Velazquez, Joaquez Andreu, and Sahuquilo (2006). "Economic optimization of conjunctive use of surface water and groundwater at the basin scale", Journal of the American Water Resources Association, Vol.132, (6), pp. 454-467.

[15] Mohan, S. and Jothiprakash, V. (2000). "Fuzzy system modeling for optimal crop planning", Journal of Institution of Engineers,(India), Vol.81,pp. 09-16.

[16] Morankar, D. V., Raju, K. S., and Nagesh Kumar D. (2013). "Integrated sustainable irrigation planning with multiobjective fuzzy optimization approach", Water Resources Management, Vol. 27, (13), pp. 3981-4004.

[17] Nikam, N. G. and Regulwar, D. G. (2015). “Optimal operation of multipurpose reservoir for irrigation planning with conjunctive use of surface and groundwater" Journal of Water Resources and Protection, Vol. 7, (8), pp, 636-646.

[18] Prasad, A. Srinivasa, Umamahesh, N. V., and Viswanath, G. K. (2006). "Optimal irrigation planning under water scarcity", Journal of Irrigation and Drainage Engineering, Vol. 32, pp. 228-237.

[19] Regulwar D. G., Anand Raj P. (2008). "Development of 3-D optimal surface of operation policies of a multireservoir in fuzzy environment using genetic algorithm for river basin development", Water Resources Management, Vol. 22, pp. 595-610. 
[20] Regulwar, D. G., and Gurav, J. B. (2010). "Fuzzy approach based management model for irrigation planning", Journal of Water Resources and Protection, Vol. 2, pp. 545-554.

[21] Regulwar, D. G., and Gurav, J. B. (2011). "Irrigation planning under uncertainty - A multi objective fuzzy linear programming approach", Journal of Water Resources Management, Vol.25, (5), pp. 1387-1416.

[22] Regulwar, D. G., and Pradhan V. S. (2013). "Irrigation planning with conjunctive use of surface and groundwater using fuzzy resources", Journal of Water Resources and Protection, Vol.5, pp. 816-822.

[23] "Revised Project Report Jayakwadi Project Stage I", Irrigation Department, Government of Maharashtra, Maharashtra, India.

[24] Sethi, L. N., Nagesh Kumar D., Nath, P. S., and Chandra, M. B. (2002). "Optimal crop planning and conjunctive use of water resources in a coastal river basin", Water Resources Management, Springer, Vol. 16, pp. 145-169.

[25] Vedula, S., Mujumdar, P.P., and Chandra Sekhar, G. (2005). "Conjunctive use modeling for multicrop irrigation”, Agricultural Water Management, Vol.73, pp.193-221.

[26] Yeh, WW-G (1985). "Reservoir management and operation models: A state-of-the-art review", Water Resour Res, 21 (12), pp. 1797-1818. 